\title{
The crystal structure of oxy hemoglobin from high oxygen affinity bird emu (Dromaius novaehollandiae)
}

\author{
Mohamed H. Mohamed Abubakkar ${ }^{1}$, Kadhirvel Saraboji ${ }^{2}$ and Mon Nanjappa G. Ponnuswamy ${ }^{1}$ \\ ${ }^{1}$ Centre of Advanced Study in Crystallography and Biophysics, University of Madras, Guindy Campus, Chennai 600 025, India \\ 2 Department of Bioinformatics, Protein Crystallography Laboratory, School of Chemical and Biotechnology, SASTRA Uni- \\ versity, Thanjavur 613 401, India
}

\begin{abstract}
Hemoglobin is an honorary enzyme, a two-way respiratory carrier, transporting oxygen from the lungs to the tissues and facilitating the return transport of carbon dioxide. Hemoglobin has high affinity for oxygen and low affinity for carbon dioxide and other substances in the arterial circulation, whereas in the venous circulation these relative affinities are upturned. The oxygen affinity of hemoglobin increases with the fall in temperature and decreases with the increase in $\mathrm{pH}$ and 2, 3-bisphosphoglycerate; point mutations also affect the tetrameric arrangement and alter the oxygen affinity. Though several studies have revealed the specific reasons for the adaptation of increased oxygen affinity of avian hemoglobins at high-altitudes, further structural insights on hemoglobins from high oxygen affinity species are required to understand the detailed oxygen adaptation at the molecular level. Herein, we describe the structural investigation of hemoglobin from emu (Dromaius novaehollandiae), a high oxygen affinity bird. Hemoglobin from emu was purified using anion-exchange chromatography, crystallized and determined the structure in the oxy form at a resolution of $2.3 \AA$; the R-factor of the model was $19.2 \%$. The structure was compared with other oxy hemoglobins of high oxygen affinity avian species; significant changes are noted at intra-subunit contacts which provide the clues for increased oxygen affinity of emu hemoglobin.
\end{abstract}

Key words: Hemoglobin - Crystal structure - Oxygen affinity $-\mathrm{pH}$

\section{Introduction}

Hemoglobin $(\mathrm{Hb})$ is functionally similar in all species, which carries oxygen from lungs to tissues and direct the return transport of carbon dioxide from tissues to the lungs. The oxygen transport mechanism of hemoglobin provides the understanding of the respiratory system and environmental

Electronic supplementary material. The online version of this article (doi: 10.4149/gpb_2014019) contains supplementary material.

Correspondence to:Kadhirvel Saraboji, Department of Bioinformatics, Protein Crystallography Laboratory, School of Chemical and Biotechnology, SASTRA University, Thanjavur 613 401, India

E-mail: saraboji@scbt.sastra.edu

Mon Nanjappa G. Ponnuswamy, Centre of Advanced Study in Crystallography and Biophysics, University of Madras, Guindy Campus, Chennai 600 025, India

E-mail: mnpsy2004@yahoo.com adaptation characteristics (Wells 1999). Hemoglobin molecule consists of four subunits $\alpha 1-\beta 1$ and $\alpha 2-\beta 2$ arranged as dimers in a fashion having pseudo two-fold symmetry and each subunit carries a specific functional prosthetic heme group attached to a $\mathrm{Fe}^{2+}$ ion. Earlier investigations clearly demonstrated that the two-state models of hemoglobin exists in equilibrium between the tense " $\mathrm{T}$ " state and the relaxed "R" state (Monod et al. 1965) mediated by the allosteric transition between the interfaces in the subunits (Perutz et al. 1987). Further, intermediate conformational states between $T$ and $R$ (R3, RR2, R2) were also observed from several crystallographic studies (Smith et al. 1991; Silva et al. 1992; Smith and Simmons 1994; Schumacher et al. 1997; Safo and Abraham 2005).

Of the various species, birds need high energy which is fulfilled with the increased supply of oxygen through metabolic pathways (Perutz 1983; Weber 2007). The respiratory system of avian species differ from the mammals and a number of investigations showed that oxygen affinity of 
avian species is higher than the mammals (Faraci 1991; Liang et al. 2001a, 2001b). However, the hemoglobin from birds is functionally similar to mammalians and regulated by inositol pentaphosphate (IPP) in place of 2,3-diphosphoglycerate (DPG) as an allosteric effector (Lenfant et al. 1969; Torrance and Bartlett 1970). Further studies on the hemoglobin structures show the altered oxygen affinity upon amino acid substitutions at heme-protein contacts and the inter-subunit contacts which orchestrates the oxy and deoxy transition states of the tetramer (Jessen et al. 1991; Vallone et al. 1996; Thom et al. 2013). It has been shown that the waterfowl species, the bar-headed goose is characterized by a remarkably higher $\mathrm{Hb}-\mathrm{O}_{2}$ affinity than greylag goose (Petschow et al. 1977; Rollema and Bauer 1979), because of the Pro a119(H2) $\rightarrow$ Ala substitution which disrupts an important intradimer van der Waals contact (Perutz 1983).

Site-directed mutagenesis studies on human hemoglobin representing the mutations observed in the high altitude geese [bar-headed goose (Pro a119 $\rightarrow$ Ala) and Andean goose (Leu $\beta 55 \rightarrow$ Ser)] show that engineered $\mathrm{Hb}$ mutant was characterized by higher oxygen binding affinity than native human $\mathrm{Hb}$ and confirm that the difference in the affinity was primarily due to the loss of a single $\alpha 1-\beta 1$ interchain contact (Jessen et al. 1991; Weber et al. 1993). Similarly, the regulation of higher oxygen affinity of vulture, a very high altitude bird, was also evidenced by the substitutions at the $\alpha_{1}-\beta_{1}$ and $\alpha_{1}-\beta_{2}$ interfaces by the mutations Thr $\alpha 34 \rightarrow$ Ile and Gln $\alpha 38 \rightarrow$ Pro contacts (Hiebl et al. 1988). Further studies show the substitutions involving the $\mathrm{C}$-terminal residues of the $\beta$ chain or of the BPG (2,3-bisphosphoglyceric acid) binding sites favor the oxygenated conformation and cause a left shift of the oxygen dissociation curve, which reflects an increased blood affinity for oxygen (Marengo-Rowe 2006). The emu bird (D. novaehollandiae) is the second largest living ratite in avian species and its hemoglobin encompass high oxygen affinity to run at a high speed of about $48 \mathrm{~km} / \mathrm{h}$ (Davies 2003). They travel long distances to find food; they feed on a variety of plants and insects, but have been known to go weeks without food. Emu's hemoglobin plays an important role for their tremendous metabolic rate and adaptation of irregular hypoxic environment (Maloney et al. 1998). The amino acid sequence of bird Hbs always shows certain distinctive patterns and it is therefore of interest whether these lead to altered structures. Further, the detailed structures of avian Hbs, particularly high oxygen affinity Hbs are limited (Zhang et al. 1996; Liang et al. 2001b; Liu et al. 2001). In the present study we focus our investigations on three-dimensional structure of emu hemoglobin and the conformational changes among the high altitude adaptation of birds. This study provides some valuable clues on higher oxygen- affinity of the bird emu. Herein, we have performed the purification and crystallization of hemoglobin under unbuffered condition which reflect the physiological $\mathrm{pH}$ of hemoglobin. The three-dimensional structure was determined using molecular replacement procedure and compared with the hemoglobins of high oxygen affinity species.

\section{Materials and Methods}

\section{Isolation and purification}

Emu hemoglobin was purified and crystallized according to our previously established procedure (Mohamed Abubakkar et al. 2013). Fresh whole blood from healthy adult emu bird was collected and $10 \mathrm{ml}$ of the blood was subsequently treated with $3 \mathrm{ml}$ of $0.9 \%(\mathrm{w} / \mathrm{v})$ saline solution containing $0.5 \mathrm{~g}$ EDTA to avoid clotting and incubated at $4^{\circ} \mathrm{C}$ for 30 minutes. Then the red blood cells (RBC) were isolated from the whole blood by centrifugation for $30 \mathrm{~min}$ at $10000 \mathrm{rpm}$ at $4^{\circ} \mathrm{C}$. The isolated RBC pellet was washed three times in two volumes of $0.9 \%(\mathrm{w} / \mathrm{v})$ isotonic saline solution and hemolysed by the addition of three times the volume of triple-distilled water. Maximum yield of cell-free hemoglobin solution as the supernatant was achieved after 90 min of hemolysation and subsequent centrifugation at $10000 \mathrm{rpm}$ at $4^{\circ} \mathrm{C}$ for $1 \mathrm{~h}$. The hemoglobin solution was carefully removed by suction and extensively dialyzed in distilled water for $48 \mathrm{~h}$, changing the distilled water for once in $12 \mathrm{~h}$. Finally, the sample was lyophilized and stored at $4^{\circ} \mathrm{C}$.

The partially purified emu hemoglobin sample was reconstituted with distilled water and loaded onto a DEAE-Cellulose anion exchange chromatographic column $(10 \times 1.5 \mathrm{~cm})$ equilibrated with water (Knapp et al. 1999). The column was initially eluted with water, followed by sodium chloride concentration gradient $(0.2-1.0 \mathrm{M}$, at a step of $0.1 \mathrm{M})$ at a flow rate of $3 \mathrm{ml} / \mathrm{min}$. The purified sample corresponding to a single peak was obtained at $0.2 \mathrm{M} \mathrm{NaCl}$. The fractions showing single peak were pooled and the homogeneity of the purified emu hemoglobin was confirmed by $10 \%$ nativePAGE (Davis 1964) and UV absorption peak at $278 \mathrm{~nm}$ (Fig. 1A, B). Protein concentration was estimated as $20 \mathrm{mg} / \mathrm{ml}$ using Bradford absorption method (Bradford 1976) using BSA as standard. Further the purified hemoglobin sample was dialyzed in distilled water and used for crystallization to perform X-ray diffraction studies.

\section{Crystallization}

The purified emu hemoglobin was crystallized at $20^{\circ} \mathrm{C}$ using hanging-drop vapour-diffusion method. The purified sample was further concentrated using Millipore centrifugal concentrator devices and the protein concentration of 20 $\mathrm{mg} / \mathrm{ml}$ was used in the initial crystallization screen using different precipitants such as 2-methyl-2,4-pentanediol 
(MPD) and polyethylene glycol (PEG; molecular weight ranges between 400 and 8000 ) as well as varying the protein concentration and $\mathrm{pH}$. The crystals appeared in different buffer conditions; however the crystals grown in unbuffered condition diffracts better, in which the crystallization drop was prepared by mixing $3 \mu \mathrm{l}$ of protein solution $(20 \mathrm{mg} / \mathrm{ml})$ and $1 \mu$ lof precipitant solution (30\% PEG 3350), equilibrated against $1 \mathrm{ml}$ reservoir solution comprising 30\% PEG 3350 without any buffer or additives. The crystals that appeared in buffered reservoir solution (25\% PEG 3350+sodium phosphate buffer, pH 6.3; 25\% PEG 3350+HEPES, pH 8.0) were highly mosaic and diffracted poorly (Supplementary Figure 1). The $\mathrm{pH}$ of unbuffered reservoir solution and equilibrated drop were observed as 7.0 (using electrode and $\mathrm{pH}$-indicator strips (Whatman) respectively), which is similar to the physiological $\mathrm{pH}$ of hemoglobin found in the peripheral tissues (Voet et al. 2008). The crystals appeared overnight and grew within two days to dimensions of 0.4 $\times 0.3 \times 0.2 \mathrm{~mm}$. The microscopic images of the crystals are shown in Fig. 1C.

\section{Data collection and processing}

$\mathrm{X}$-ray diffraction data were collected at the in-house G. N. Ramachandran X-ray facility using MAR345dtb image plate detector and a Bruker Microstar copper rotatinganode generator operating at $45 \mathrm{kV}$ and $60 \mathrm{~mA}$. To collect the diffraction data under cryogenic conditions, crystals of emu hemoglobin were soaked for 30-40 seconds in a cryoprotectant solution containing the reservoir solution supplemented with $25 \%(\mathrm{v} / \mathrm{v})$ glycerol before flash-cooling in a stream of liquid nitrogen at $-173^{\circ} \mathrm{C}$. Data were processed and scaled using AUTOMAR software suite (Klein 2009). The crystals diffracted to $2.3 \AA$ resolution, and statistics of the crystallographic data collection and processing are presented in Table 1.

\section{Structure determination, model building and refinement}

The diffracted crystal belongs to orthorhombic space group which accommodates one whole biological molecule ( $\alpha 1 \beta 1$, $\alpha 2 \beta 2$ ) in the asymmetric unit with a solvent content of $47 \%$ (Matthews 1968; Kantardjieff and Rupp 2003). The structure was solved by the molecular replacement method using the program Phaser (McCoy et al. 2007) from the CCP4 program suite (Potterton et al. 2003; Winn et al. 2011) using ostrich hemoglobin (Sundaresan et al. 2009; PDB id: 3FS4) as a starting model. The structure solution showed no steric clashes between symmetry-related molecules and good crystal packing with the likelihood gain of 2225. As the amino acid sequence of $\beta$ subunit of emu hemoglobin is not available, the model building of $\beta$ subunit is performed by identifying the consensus residues using multiple sequence
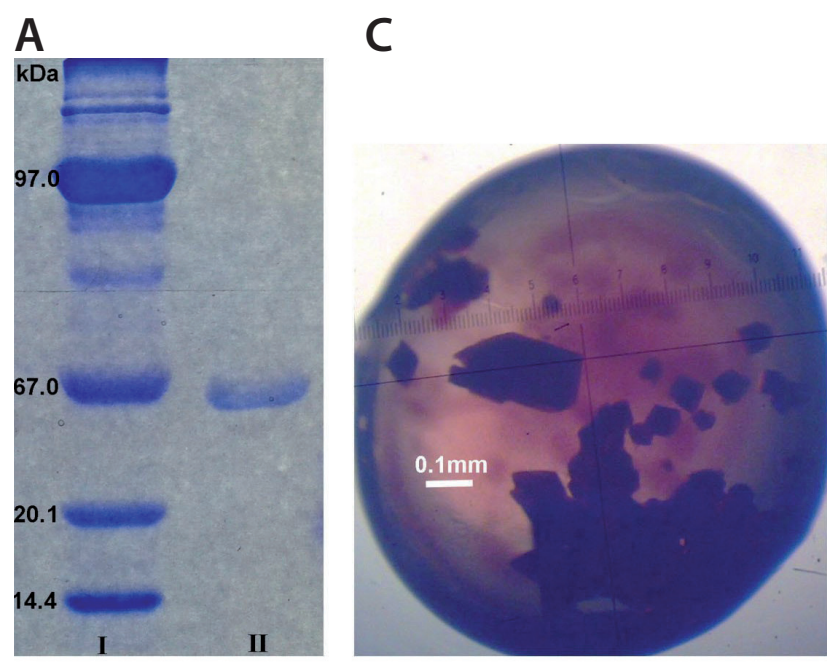

B

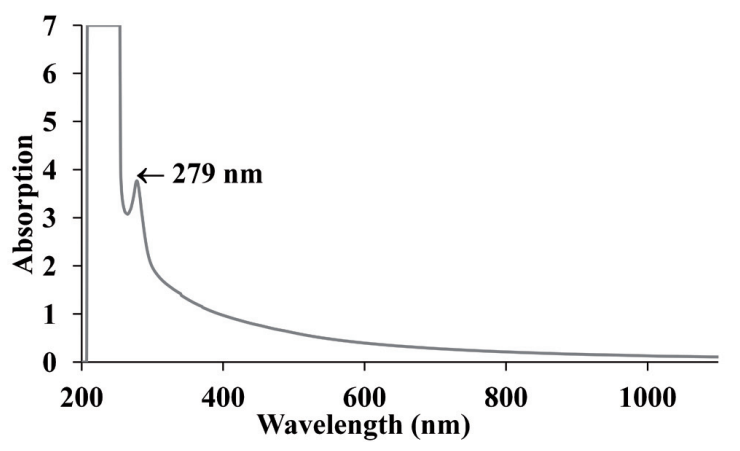

Figure 1. A. Native PAGE showing purified emu hemoglobin in lane-II (mw: $66.5 \mathrm{kDa}$ ) and the molecular weight standards in lane-I. B. The UV absorption spectra of the purified hemoglobin showed a single peak at $279 \mathrm{~nm}$. C. Crystals of emu hemoglobin grown under unbuffered condition.

alignment of 149 avian sequences including 2 ratites (Supplementary Data 1). Interestingly, the amino acid sequence deduced from the $\beta$ subunit of the model shares high similarity (95\% identity) with the hemoglobins of high oxygen affinity species, vulture and geese, suggesting that the evolution of increased oxygen affinity can be attributed to similar changes with similar mechanism. Indirectly, the consistency between the electron density and amino acids derived through multiple sequence alignment indicates that electron density at $2.3 \AA$ resolution is clear and reliable enough. Also, in $\alpha 1-\beta 1$ dimer, the electron density clearly resolves the side chain orientations of twenty-five substitutions with respect to ostrich hemoglobin (starting model). The structures were refined using Refmac5 (Murshudov et al. 1997) through CCP4i interface (Potterton et al. 2003), with the maximum likelihood target function and using anisotropic B factors. Five percent of the total reflections were flagged randomly for cross validation before refine- 
Table 1. Crystallographic data-collection and model refinement statistics of $\mathrm{Hb}$ from $D$. novaehollandiae (values in parentheses correspond to the highest resolution shell)

\begin{tabular}{|c|c|}
\hline \multicolumn{2}{|l|}{$X$-ray diffraction data collection } \\
\hline X-ray Source & $\mathrm{Cu} \mathrm{Ka}$ \\
\hline Wavelength $(\AA)$ & 1.5417 \\
\hline Crystal dimensions (mm) & $0.4 \times 0.3 \times 0.2$ \\
\hline Rotation range per image $\left({ }^{\circ}\right)$ & 1 \\
\hline Total rotation range $\left(^{\circ}\right)$ & 180 \\
\hline Exposure time per image (s) & 60 \\
\hline Space group & $\mathrm{P} 2{ }_{1}{ }_{1} 2_{1}$ \\
\hline Unit cell parameters $(\AA)$ & $\begin{array}{l}a=66.27, b=80.01 \\
c=103.55\end{array}$ \\
\hline Mosaicity $\left(^{\circ}\right)$ & 0.20 \\
\hline Resolution $(\AA)$ & $30.0-2.3(2.35-2.30)$ \\
\hline No. of measured reflections & 178094 \\
\hline No. of unique reflections & 25129 \\
\hline Data completeness (\%) & $99.5(100)$ \\
\hline Multiplicity & 7.0 \\
\hline $\mathrm{R}_{\text {merge }}(\%)^{\mathrm{a}}$ & $6.1(26.2)$ \\
\hline$<\mathrm{I} / \sigma(\mathrm{I})>$ & $6.4(2.0)$ \\
\hline \multicolumn{2}{|l|}{ Refinement } \\
\hline Resolution range $(\AA)$ & $30.0-2.3(2.35-2.30)$ \\
\hline $\mathrm{R}_{\text {model }}(\%)^{\mathrm{b}}$ & $19.2(21.8)$ \\
\hline $\mathrm{R}_{\text {free }}(\%)^{\mathrm{c}}$ & $25.6(33.0)$ \\
\hline $\begin{array}{l}\text { Residues in the asymmetric unit } \\
\text { (water molecules) }\end{array}$ & $568(360)$ \\
\hline Mean B factor $\left(\AA^{2}\right)$ [protein (water)] & $20.7(26.9)$ \\
\hline r.m.s deviation: bond lengths $(\AA)$ & 0.018 \\
\hline r.m.s deviation: bond angles $\left(^{\circ}\right)$ & 1.579 \\
\hline \multicolumn{2}{|l|}{ Ramachandran plot ${ }^{\mathrm{d}}$} \\
\hline most favored (\%) & 91.7 \\
\hline additionally allowed (\%) & 7.8 \\
\hline generously allowed (\%) & 0.6 \\
\hline \multicolumn{2}{|c|}{$\begin{array}{l}{ }^{\mathrm{a}} \mathrm{R}_{\text {merge }}=\sum_{\mathrm{hkl}} \sum_{\mathrm{i}}\left|\mathrm{I}(h k l)_{\mathrm{i}}-<\mathrm{I}(h k l)>\right| / \sum_{\mathrm{hkl}} \sum_{\mathrm{i}}<\mathrm{I}(h k l)_{\mathrm{i}}>;{ }^{\mathrm{b}} \mathrm{R}_{\text {model }} \\
=\sum_{\mathrm{hkl}}\left|\mathrm{F}_{\mathrm{o}}(h k l)-\mathrm{F}_{\mathrm{c}}(h k l)\right| / \sum_{\mathrm{hkl}}\left|\mathrm{F}_{\mathrm{o}}(h k l)\right| \text {, where } \mathrm{F}_{\mathrm{o}} \text { and } \mathrm{F}_{\mathrm{c}} \text { are the } \\
\text { observed and calculated structure factors, respectively. }{ }^{\mathrm{c}} \mathrm{R}_{\text {free }} \text { was } \\
\text { calculated using } 5.0 \% \text { of the total reflections. }{ }^{\mathrm{d}} \text { Calculated with } \\
\text { PROCHECK (Laskowski et al. 1993). }\end{array}$} \\
\hline
\end{tabular}

ment. TLS (Translation-Libration-Screw) parametrization was used in the latter stage of refinement, with one set of parameters for each chain (Winn et al. 2001). Structures were visualized and modified using Coot5 (Emsley and Cowtan 2004). The water molecules in the structure, including heme coordinated oxygens were identified and accounted by electron density peaks greater than $3 \sigma$ in Fo-Fc map and $1 \sigma$ in 2Fo-Fc map. The stereochemistry of the model was evaluated with PROCHECK (Laskowski et al. 1993) and the structural alignments were made using the SSM algorithm (Krissinel and Henrick 2004) as implemented in Coot5. Refinement and geometrical statistics of present model are summarized in Table 1. The atomic coordinates and structure factors of emu Hb have been deposited in the RCSB Protein Data Bank (www.pdb.org) as an entry code 3WTG.

\section{Results and Discussion}

\section{Overall structure}

The final refined model of emu $\mathrm{Hb}$ contains one tetrameric unit of $\mathrm{Hb}$ having two $\alpha$ chains $(\alpha 1, \alpha 2)$ and two $\beta$ chains $(\beta 1, \beta 2)$. There are seven and eight helices in $\alpha$ and $\beta$ chains, respectively, comprising $568 \mathrm{Hb}$ amino acid residues, 4 heme groups, 4 oxygen molecules and 360 water molecules. The $2 \mathrm{Fo}-\mathrm{Fc}$ electron density map at $1.0 \sigma$ shows continuous density for the entire polypeptide main chain and side chain atoms. The final model confirms the oxy form of emu hemoglobin. In emu $\mathrm{Hb}$, all four heme groups, as well as the $\mathrm{O}_{2}$ molecules are well-defined by electron density in both 2 Fo-Fc and omit maps. The individual $\alpha, \beta$ subunits and the overall model are similar to avian Hbs; and comparable to oxy Hbs of the high oxygen affinity species, namely barheaded goose (Zhang et al. 1996) and greylag goose (Liang et al. 2001b), with the r.m.s.d (root-mean-square deviation) values of 0.64 and $0.63 \AA$, respectively (Fig. 3A). However, a subunit shows larger deviation than in $\beta$ subunits (r.m.s.d. of 0.65 and $0.55 \AA$ with bar-headed and greylag goose oxy

Table 2. Comparison of the overall structure of emu oxy $\mathrm{Hb}$ with oxy Hbs from bar-headed goose (PDB id: 1A4F), greylag goose (PDB id: 1FAW), ostrich (PDB id: 3FS4) and human (PDB id: 1HHO)

\begin{tabular}{lcccc}
\hline \multirow{2}{*}{ Subunits } & \multicolumn{4}{c}{ r.m.s.d. values (in Å) between Emu and: } \\
\cline { 2 - 5 } & Bar-headed goose & Grey lag goose & Ostrich & Human \\
\hline a subunit & 0.650 & 0.545 & 0.612 & 0.781 \\
$\beta$ subunit & 0.424 & 0.395 & 0.272 & 0.885 \\
a1 $\beta 1$ dimer & 0.667 & 0.552 & 0.669 & 0.889 \\
tetramer & 0.635 & 0.628 & 0.663 & 1.053 \\
\hline
\end{tabular}

Root mean square deviation (r.m.s.d) was calculated by least-squares superposition of protein main chain atoms using Superpose algorithm (Krissinel and Henrick 2004). 

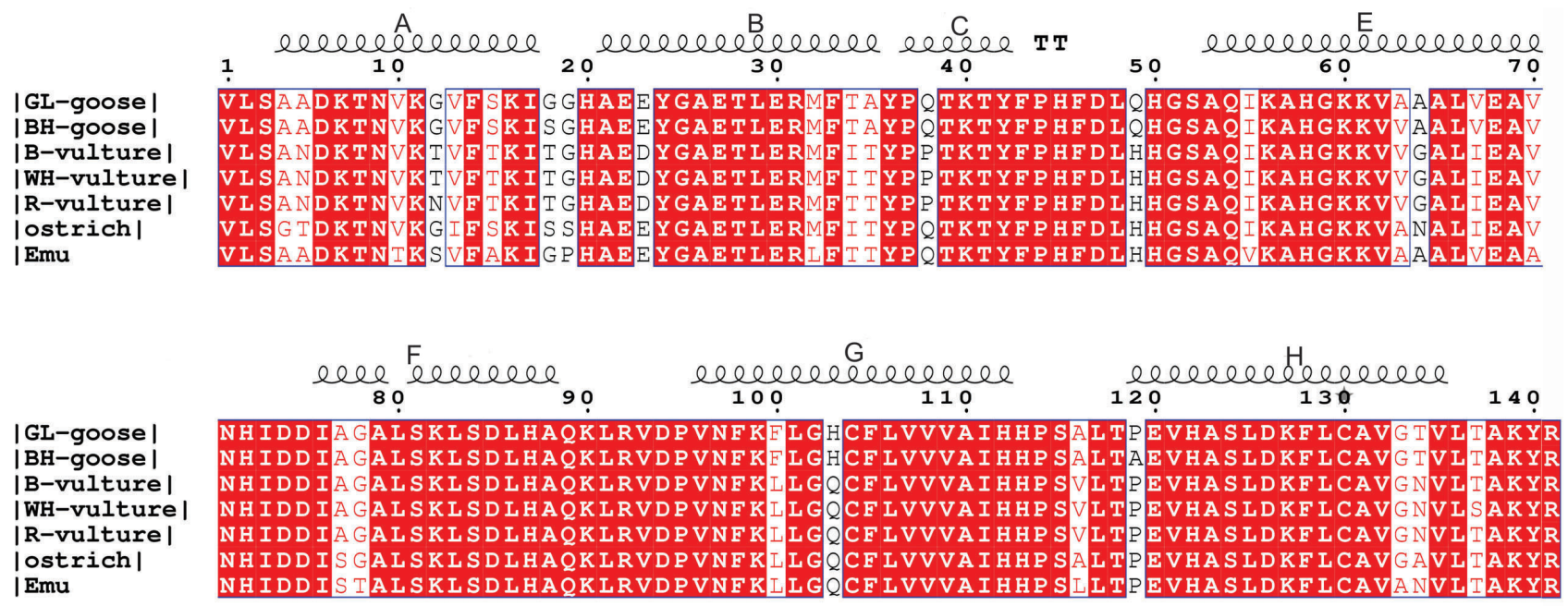

Figure 2. Multiple sequence alignment of the emu $\mathrm{Hb}$ ( $\alpha$ subunit) with Hbs from high altitude birds (GL-goose, greylag goose; BH-goose, bar-headed goose; B-vulture, black vulture; WH-vulture, white-headed vulture; R-vulture, Rüppell's vulture and ostrich). The alignment was made using ClustalW algorithm (Larkin et al. 2007). The $\alpha$ - helical segments are denoted.

Hbs, respectively) due to the effect of more amino acid substitutions in this subunits. Table 2 reveals the r.m.s. deviations between emu oxy $\mathrm{Hb}$ and other oxy Hbs. The amino acid sequence comparison of high altitude birds shows that $a$ subunit of emu's hemoglobin shares $88 \%$ and $86 \%$ similarity with the oxy Hbs of vulture and geese, respectively (Fig. 2); particularly, of the 141 amino acids in a subunit, 19 substitutions occurred at the helices A, B, E, F, G and H. With respect to human $\mathrm{Hbs}$, the $\alpha$ and $\beta$ subunits of emu shares $69 \%$ and $68 \%$ sequence identity, respectively.

Table 3. Geometry of the heme groups and its environment residues in oxy hemoglobins (oxy Hb)

\begin{tabular}{|c|c|c|c|c|c|c|}
\hline $\mathrm{Oxy} \mathrm{Hb}$ & Subunit & $\begin{array}{c}\text { Fe-His(E7)NE2 } \\
(\AA)\end{array}$ & $\begin{array}{c}\mathrm{Fe}-\operatorname{Val}(\mathrm{E} 11) \mathrm{CG} 2 \\
(\AA)\end{array}$ & $\begin{array}{c}\text { Fe-Phe }(\mathrm{CD} 1) \mathrm{CZ} \\
(\AA)\end{array}$ & $\begin{array}{c}\mathrm{Fe}-\mathrm{His}(\mathrm{F} 8) \mathrm{NE} 2 \\
(\AA)\end{array}$ & $\begin{array}{c}\text { Fe-Plane distance } \\
(\AA)\end{array}$ \\
\hline \multirow{4}{*}{ Emu } & $\alpha 1$ & 4.44 & 4.86 & 5.58 & 1.96 & 0.14 \\
\hline & $\beta 1$ & 4.34 & 4.65 & 5.46 & 2.08 & 0.19 \\
\hline & $a 2$ & 4.54 & 4.81 & 5.36 & 2.07 & 0.12 \\
\hline & $\beta 2$ & 4.37 & 4.82 & 5.56 & 2.01 & 0.13 \\
\hline \multirow{4}{*}{ Bar-headed goose } & $a 1$ & 4.52 & 5.06 & 5.66 & 2.10 & 0.21 \\
\hline & $\beta 1$ & 4.51 & 4.90 & 5.64 & 2.07 & 0.13 \\
\hline & $a 2$ & 4.52 & 5.06 & 5.66 & 2.10 & 0.21 \\
\hline & $\beta 2$ & 4.51 & 4.90 & 5.64 & 2.07 & 0.13 \\
\hline \multirow{4}{*}{ Greylag goose } & $\alpha 1$ & 4.49 & 5.19 & 5.60 & 2.19 & 0.26 \\
\hline & $\beta 1$ & 4.45 & 4.89 & 5.63 & 2.14 & 0.16 \\
\hline & $a 2$ & 4.49 & 5.19 & 5.60 & 2.19 & 0.26 \\
\hline & $\beta 2$ & 4.49 & 4.89 & 5.63 & 2.14 & 0.16 \\
\hline \multirow{4}{*}{ Ostrich } & $\alpha 1$ & 4.27 & 4.99 & 5.56 & 2.12 & 0.19 \\
\hline & $\beta 1$ & 4.14 & 4.70 & 5.44 & 2.17 & 0.14 \\
\hline & $\alpha 2$ & 4.40 & 4.79 & 5.54 & 1.96 & 0.13 \\
\hline & $\beta 2$ & 4.19 & 4.66 & 5.27 & 2.12 & 0.12 \\
\hline \multirow{4}{*}{ Human } & $\alpha 1$ & 4.39 & 4.79 & 5.51 & 1.94 & 0.16 \\
\hline & $\beta 1$ & 4.19 & 4.66 & 5.66 & 2.07 & 0.06 \\
\hline & $a 2$ & 4.39 & 4.79 & 5.51 & 1.94 & 0.16 \\
\hline & $\beta 2$ & 4.19 & 4.66 & 5.66 & 2.07 & 0.06 \\
\hline
\end{tabular}

* The plane is defined as that passing through all heme atoms excluding the side chains and the Fe atom. 


\section{Heme environment}

The final model shows a clear 2Fo-Fc electron density at 1.0 $\sigma$ level at the distal side of heme plane in all four subunits in the asymmetric unit, which authenticates the oxy form of emu hemoglobin. The heme pockets of emu $\mathrm{Hb}$ are similar to those of human $\mathrm{Hb}$ (Shaanan 1983) and high oxygen affinity birds (greylag goose, bar-headed goose and ostrich) and there are no mutations in the heme vicinity. The heme regions of the molecule are well conserved and the equivalent residues overlap closely. The heme and the residues around it in the emu oxy $\mathrm{Hb}$ structure fit well to electron densities. Figure 3B shows the fitted superposition of heme pockets of emu and other species Hbs refined through least-squares procedures. A comparison of the geometries around the heme group between the emu oxy $\mathrm{Hb}$ and oxy $\mathrm{Hbs}$ is given in Table 3.

A

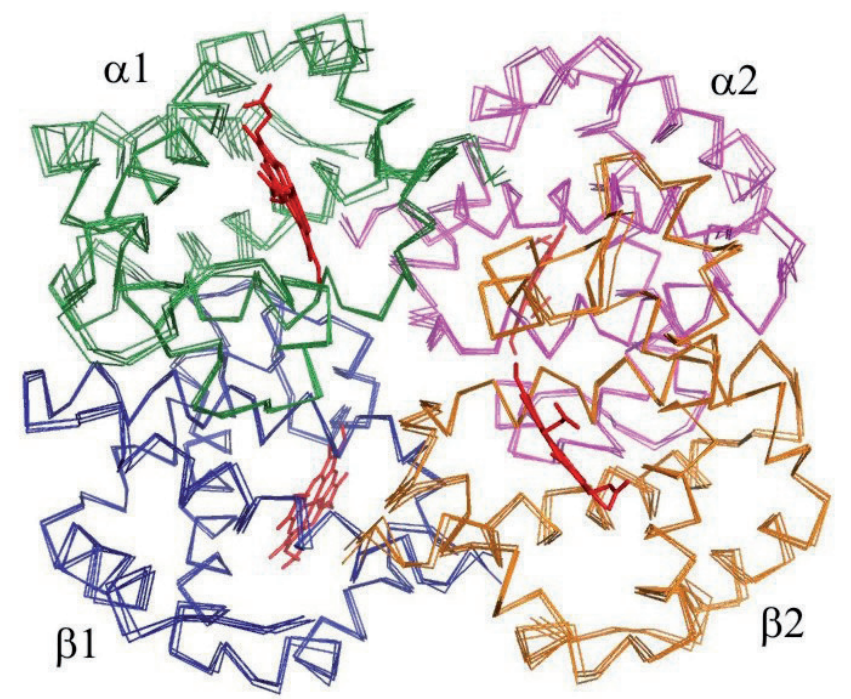

B
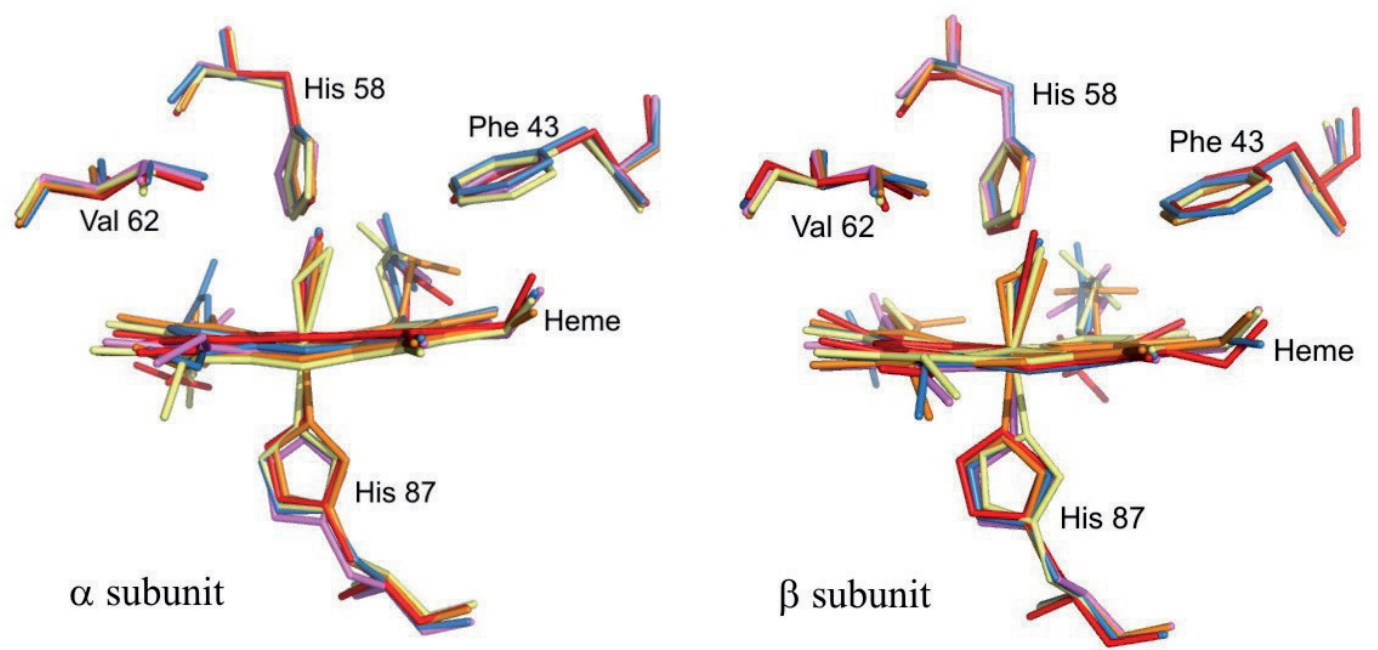

Figure 3. A. Structural superposition of the Ca traces of oxy Hbs of emu, bar-headed goose (PDB id: 1A4F), greylag goose (PDB id: 1FAW), ostrich (PDB id: 3FS4) and human (PDB id: 1HHO) showing overall similarity. The molecules are shown in thin lines and the heme is shown in stick representation. B. Structural superposition of the heme pocket of the emu oxy Hb (black/orange) on oxy Hbs of bar-headed goose (grey/blue), greylag goose (white/pink), ostrich (grey-thin sticks/yellow) and human (white-thin sticks/red). [Molecule colors according to $\mathrm{B} \& \mathrm{~W} /$ color version] 


\section{Inter and intra subunit interactions}

In common with other $\mathrm{Hbs}$, emu hemoglobin structure has extensive intradimer $(\alpha 1-\beta 1 / \alpha 2-\beta 2)$ packing contacts amounting to 29 residues, whereas interdimer ( $\alpha 1-\beta 2$ / $\alpha 2-$ $\beta 1$ ) sliding contacts were less with the involvement of 13 residues. In order to maintain the free-energy difference between the T- and R-states (Pettigrew et al. 1982; Dickerson and Geis 1983), the highly conserved inter-subunit slide contacts in emu $\mathrm{Hb}$ are also similar to other vertebrate Hbs.

The $\alpha 1-\beta 1 / \alpha 2-\beta 2$ dimer interface of emu oxy $\mathrm{Hb}$ contains similar non-covalent interactions as in the case of oxy state $\mathrm{Hb}$ structures of high altitude/high oxygen affinity birds, bar-headed goose (Zhang et al. 1996), greylag goose (Liang et al. 2001b) and ostrich (Sundaresan et al. 2009). In fact, the residues involved in hydrogen bonding and ion pair interactions at this interface are conserved in these four $\mathrm{Hb}$ structures, except the substitutions in geese at Thr a35(B16) $\rightarrow$ Ala, Gln a103(G10) $\rightarrow$ His. In particular, the amino acids responsible for the elevated $\mathrm{O}_{2}$ affinity of adult Hbs of the geese and vulture [Thr a34(B15), Gln a38(C3), Pro a119(H2) (except bar-headed goose)] are highly similar in the emu $\mathrm{Hb}$ structure (Hiebl et al. 1988; Jessen et al. 1991; Weber et al. 1993), where as in human $\mathrm{Hb}, 34$ and 38 positions were substituted with Leu and Thr, respectively.

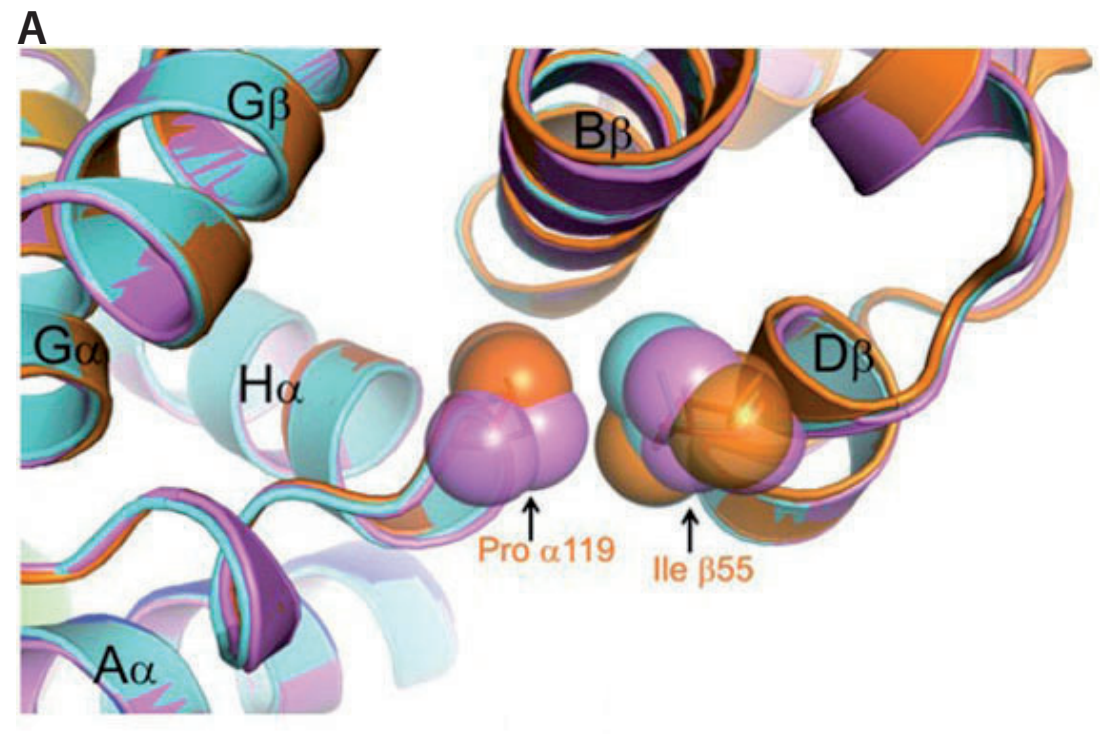

B

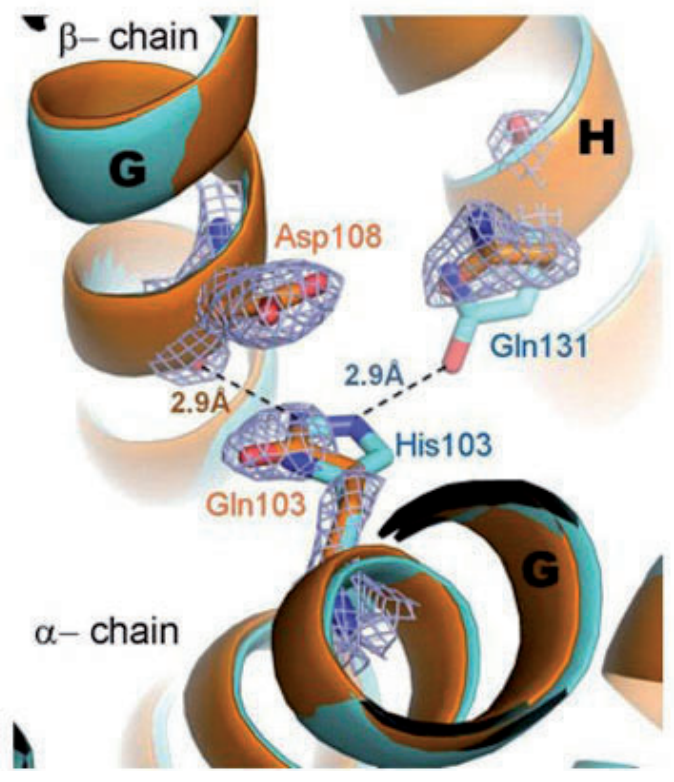

Figure 4. A. Variation in the van der Waals contacts between $\alpha 119(\mathrm{H} 2)$ and $\beta 55(\mathrm{D} 6)$ in oxy Hbs of emu (black/orange), bar-headed goose (grey/blue) and greylag goose (white/pink). van der Waals radius of side chain atoms are shown in spheres. In barheaded goose $\mathrm{Hb}$, the contact disrupts due to Pro $\alpha 119(\mathrm{H} 2) \rightarrow$ Ala substitution, where as in emu $\mathrm{Hb}$, the substitution in $\beta$ subunit, Leu $\beta 55(D 6) \rightarrow$ Ile, triggers similar disruption compared to greylag goose's $\mathrm{Hb}$. B. Structural comparison of hemoglobin of emu (black/orange) and bar-headed goose (grey/blue) (Zhang et al. 1996; PDB id: $1 \mathrm{~A} 4 \mathrm{~F}$ ) showing the compensation of inter-subunit interaction due to the variation in the amino acid sequence. In barheaded goose (also in greylag goose), the association of $\alpha 1-\beta 1$ subunit is stabilized by a hydrogen bond interaction between His103 ( $\alpha 1)$ and $G \ln 131(\beta 1)$, whereas emu structure is stabilized by a hydrogen bond between $\operatorname{Gln} 103(\alpha 1)$ and Asp108 ( $\beta 1)$. The $2 \mathrm{Fo}-\mathrm{Fc}$ electron density map is shown around the emu hemoglobin residues contoured at $1.0 \sigma$ level. [Molecule colors according to $\mathrm{B} \& \mathrm{~W} /$ color version] 
Here in, Pro a119(H2) $\rightarrow$ Ala substitution is found to be interesting in the avian Hbs as it disrupts an important intradimer van der Waals contact between Pro a119(H2) and Leu $\beta 55$ (D6), which is responsible for the higher $\mathrm{O}_{2}$ affinity of bar-headed goose $\mathrm{Hb}$ than greylag goose and vulture (Perutz 1983). Although Pro a119(H2) is unaltered in the emu oxy $\mathrm{Hb}$ structure, the electron density clearly displays the change Leu $\beta 55$ (D6) $\rightarrow$ Ile, as in vultures, chicken, common swift, Andean condor etc. (Supplementary Figure 2 and Supplementary Data 1); as an effect of this, the significant variation in van der Waals contacts are marked in Figure 4A. The closest distance observed between Pro a 119 and Ile $\beta 55$ in emu oxy $\mathrm{Hb}$ is $4.31 \AA$, the distance comparable to bar-headed goose between Ala a119 and Ile $\beta 55$ ( $4.56 \AA$ ), whereas the distance is shorter in greylag goose and ostrich oxy Hbs (3.79 and $3.86 \AA$, respectively). The disruption of this contact due to the substitution in $\beta$ subunit (Leu $\beta 55$ (D6) $\rightarrow$ Ile) clearly dictates the reasons for the higher oxygen affinity of emu oxy $\mathrm{Hb}$. This $\beta$ subunit substitution resembles the change found in Andean goose $\mathrm{Hb}\left(\beta 55(\mathrm{D} 6) \rightarrow\right.$ Ser) which shows increased $\mathrm{O}_{2}$ affinity when engineered in the human $\mathrm{Hb}$ (Met $\beta 55 \mathrm{Ser}$ ) (Weber et al. 1993). These results shed the light in such a way that the change in $\alpha$ or $\beta$ subunits (Proa $119 \mathrm{Al}$ or Met $\beta 55$ Ser mutation) can elevate the oxygen affinity. However, the availability of complete amino acid sequence of $\beta$ subunit of emu $\mathrm{Hb}$ and protein-engineering experiments can strengthen this observation. Further, due to the local backbone perturbation of Pro a119(H2) $\rightarrow$ Ala substitution leads to loss of a hydrogen bond between Pro a119 (H2) and Arg $\beta 30$ (B12) in bar-headed goose $\mathrm{Hb}$, a notable feature preserved in emu and greylag goose Hbs.

On the other side of the interface, the new orientation of His a50 (CE8) in the emu oxy Hb stabilizes the CE loop of $\alpha$ subunit with $\mathrm{H}$-helix of $\beta$ subunit through a salt bridge with Glu $\beta 125(\mathrm{H} 3)$ at a distance of $3.30 \AA$, which is not seen in ostrich $\mathrm{Hb}$ (Supplementary Figure 3). Interestingly, the greylag goose oxy $\mathrm{Hb}$ structure proposes the possibility of such a salt bridge in one of the alternative conformations of His $\alpha 50$, at distance of $3.75 \AA$ (Liang et al. 2001b). In fact this inference is valid if the side-chain flexibility of Glu and His are considered, whereas the present emu oxy $\mathrm{Hb}$ structure authenticates the existence of such His a50 conformation and thus the salt bridge. In contrast to this, the mutation in bar-headed goose oxy Hb, Glu $\beta 125(\mathrm{H} 3)$ $\rightarrow$ Asp separates His a50 far away (8.2 $)$ ), indicating the absence of van derWaals contact, another contributing factor to the higher oxygen affinity (Zhang et al. 1996; Liang et al. 2001b). Therefore, the observed intra-subunit linkage via the salt bridge in emu oxy $\mathrm{Hb}$ suggests its $\mathrm{O}_{2}$ affinity is comparable to bar-headed goose oxy $\mathrm{Hb}$.

In addition, an intra-subunit hydrogen bond between Thr a35 (B16) and Gln $\beta 127$ (H7) is observed in emu and ostrich Hbs whereas the substitution Thr a35 (B16) $\rightarrow$ Ala in geese prevents such interaction. Further, the substitution His $\alpha 103 \rightarrow \mathrm{Gln}$ in emu $\mathrm{Hb}$, compensates the contact between His $\alpha 103$ (G10) and Gln $\beta 131$ (H9) observed in the geese structure, through hydrogen bonding between Gln $\alpha 103(\mathrm{G} 10)$ and Asp $\beta 108(\mathrm{G} 10)$ (Fig. 4B). Also the substitution Gln a103(G10) pushes away the side chain of Gln $\beta 131(\mathrm{H} 9)$, which is slightly different from the geese Hb's conformation.

\section{Conclusions}

In the present study, the crystals of emu hemoglobin were obtained at $20^{\circ} \mathrm{C}$ under neutral $\mathrm{pH}$ (unbuffered) condition and the three-dimensional structure was determined at $2.3 \AA$ resolution. Although sequence information is not available for the $\beta$ subunit of emu, the present structure is reliable as the low $\mathrm{R}$ and $\mathrm{R}_{\text {free }}$ values provide clear information on the electron density map throughout the model. The three high oxygen affinity avian oxy $\mathrm{Hb}$ structures solved so far, bar-headed goose, greylag goose and ostrich have been compared with the emu $\mathrm{Hb}$ structure to understand the reasons behind high $\mathrm{O}_{2}$ affinity of emu $\mathrm{Hb}$. Despite the overall structural similarity, the two structural hot spots (mutations at $\alpha 119-\beta 55$ and mutations $\alpha 50-\beta 125)$ are responsible for high $\mathrm{O}_{2}$ affinity and reveal the contrasting changes in the present emu oxy $\mathrm{Hb}$ (Weber et al. 1993; Zhang et al. 1996; Liang et al. 2001b). The Leu $\beta 55 \rightarrow$ Ile substitution producing a gap between $\alpha 199$ and $\beta 55$ as in the bar-headed goose $\mathrm{Hb}$, indicates the elevated $\mathrm{O}_{2}$ affinity compared to greylag goose and ostrich; whereas the strong salt bridge between His $\alpha 50-$ Glu $\beta 125$, due to the new orientation of His $\alpha 50$, can reduce considerable affinity compared to bar-headed goose $\mathrm{Hb}$. Further $\mathrm{O}_{2}$ affinity and protein engineering experiments can provide more valuable information on the exact affinity of emu $\mathrm{Hb}$ towards oxygen.

Acknowledgement. The authors thank the anonymous reviewers for their constructive comments. The authors gratefully acknowledge the Department of Biotechnology (DBT), Govt. of India for financial support to create the in-house G. N. Ramachandran X-ray facility in CAS in Crystallography and Biophysics, University of Madras, Chennai, India. Further KS gratefully acknowledges Prof. T.R. Rajagopalan Memorial Research Grant, SASTRA University and DST-SERB, Government of India for financial support through Fast Track scheme for Young Scientists.

\section{References}

Bradford M. M. (1976): A rapid and sensitive method for the quantitation of microgram quantities of protein utilizing the principle of protein-dye binding. Anal. Biochem. 72, 248-254 
http://dx.doi.org/10.1016/0003-2697(76)90527-3

Davies S. J. J. F. (2003): Tinamous and ratites to hoatzins. In: Grzimek's Animal Life Encyclopedia: Birds I, Vol. 8, pp. 83-87, Farmington Hills, MI: Gale Group

Davis B. J. (1964): Disc electrophoresis II: Method and application to human serum proteins. Ann. N. Y. Acad. Sci. 121, 404-427 http://dx.doi.org/10.1111/j.1749-6632.1964.tb14213.x

Dickerson R. E., Geis I. (1983): Hemoglobin: Structure, Function, Evolution, and Pathology. Benjamin/Cummings Publishing, Menlo Park, CA

Emsley P., Cowtan K. (2004): Coot: model-building tools for molecular graphics. Acta Crystallogr. D Biol. Crystallogr. 60, 2126-2132 http://dx.doi.org/10.1107/S0907444904019158

Faraci F. M. (1991): Adaptations to hypoxia in birds: how to fly high. Annu. Rev. Physiol. 53, 59-70 http://dx.doi.org/10.1146/annurev.ph.53.030191.000423

Hiebl I., Weber R. E., Schneeganss D., Kosters J., Braunitzer G. (1988): High-altitude respiration of birds. Structural adaptations in the major and minor hemoglobin components of adult Ruppell's Griffon (Gyps rueppellii, Aegypiinae): a new molecular pattern for hypoxic tolerance. Biol. Chem. Hoppe Seyler. 369, 217-232 http://dx.doi.org/10.1515/bchm3.1988.369.1.217

Jessen T. H., Weber R. E., Fermi G., Tame J., Braunitzer G. (1991): Adaptation of bird hemoglobins to high altitudes: demonstration of molecular mechanism by protein engineering. Proc. Natl. Acad. Sci. U.S.A. 88, 6519-6522 http://dx.doi.org/10.1073/pnas.88.15.6519

Kantardjieff K. A., Rupp B. (2003): Matthews coefficient probabilities: Improved estimates for unit cell contents of proteins, DNA, and protein-nucleic acid complex crystals. Protein Sci. 12, 1865-1871 http://dx.doi.org/10.1110/ps.0350503

Klein C. (2009): The AUTOMAR User's Guide. (v.2.6.0), MAR Research GmbH, Germany)

Knapp J. E., Oliveira M. A., Xie Q., Ernst S. R., Riggs A. F., Hackert M. L. (1999): The structural and functional analysis of the hemoglobin D component from chicken. J. Biol. Chem. 274, 6411-6420

http://dx.doi.org/10.1074/jbc.274.10.6411

Krissinel E., Henrick K. (2004): Secondary-structure matching (SSM), a new tool for fast protein structure alignment in three dimensions. Acta Crystallogr. D Biol. Crystallogr. 60, 2256-2268 http://dx.doi.org/10.1107/S0907444904026460

Larkin M. A., Blackshields G., Brown N. P., Chenna R., McGettigan P. A., McWilliam H., Valentin F., Wallace I. M., Wilm A., Lopez R., Thompson J. D., Gibson T. J., Higgins D. G. (2007): Clustal W and Clustal X version 2.0. Bioinformatics 23, 2947-2948 http://dx.doi.org/10.1093/bioinformatics/btm404

Laskowski R. A., MacArthur M. W., Moss D. S., Thornton J. M. (1993): PROCHECK: a program to check the stereochemical quality of protein structures. J. Appl. Cryst. 26, 283-291 http://dx.doi.org/10.1107/S0021889892009944

Lenfant C., Kooyman G. L., Elsner R., Drabek C. M. (1969): Respiratory function of blood of the Adelie penguin Pygoscelis adeliae. Am. J. Physiol. 216, 1598-1600
Liang Y., Hua Z., Liang X., Xu Q., Lu G. (2001a): The crystal structure of bar-headed goose hemoglobin in deoxy form: the allosteric mechanism of a hemoglobin species with high oxygen affinity. J. Mol. Biol. 313, 123-137 http://dx.doi.org/10.1006/jmbi.2001.5028

Liang Y. H., Liu X. Z., Liu S. H., Lu G. Y. (2001b): The structure of greylag goose oxy haemoglobin: the roles of four mutations compared with bar-headed goose haemoglobin. Acta Crystallogr. D Biol. Crystallogr. 57, 1850-1856 http://dx.doi.org/10.1107/S0907444901016493

Liu X. Z., Li S. L., Jing H., Liang Y. H., Hua Z. Q., Lu G. Y. (2001): Avian haemoglobins and structural basis of high affinity for oxygen: structure of bar-headed goose aquomet haemoglobin. Acta Crystallogr. Sect. D. 57, 775-783 http://dx.doi.org/10.1107/S0907444901004243

Maloney S. K., Dawson T. J. (1998): Changes in pattern of heat loss at high ambient temperature caused by water deprivation in a large flightless bird, the emu. Physiol. Zool. 71, 712-719

Marengo-Rowe A. J. (2006): Structure-function relations of human hemoglobins. Proc. (Bayl Univ Med Cent) 19, 239-245

Matthews B. W. (1968): Solvent content of protein crystals. J. Mol. Biol. 33, 491-497 http://dx.doi.org/10.1016/0022-2836(68)90205-2

McCoy A. J., Grosse-Kunstleve R. W., Adams P. D., Winn M. D., Storoni L. C., Read R. J. (2007): Phaser crystallographic software. Acta Crystallogr. D Biol. Crystallogr. 40, 658-674

Mohamed Abubakkar M., Saraboji K., Ponnuswamy M. N. (2013): Purification, crystallization and preliminary crystallographic study of haemoglobin from mongoose (Helogale parvula) in two different crystal forms induced by $\mathrm{pH}$ variation. Acta Crystallogr. Sect. F Struct. Biol. Cryst. Commun. 69, 126-129 http://dx.doi.org/10.1107/S174430911205083X

Monod J., Wyman J., Changeux J. P. (1965): On the nature of allosteric transitions: A plausible model. J. Mol. Biol. 12, 88-118 http://dx.doi.org/10.1016/S0022-2836(65)80285-6

Murshudov G. N., Vagin A. A., Dodson E. J. (1997): Refinement of macromolecular structures by the maximum-likelihood method. Acta Crystallogr. D Biol. Crystallogr. 53, 240-255 http://dx.doi.org/10.1107/S0907444996012255

Perutz M. F. (1983): Species adaptation in a protein molecule. Mol. Biol. Evol. 1, 1-28

Perutz M. F., Fermi G., Luisi B., Shaanan B., Liddington R. C. (1987): Stereochemistry of cooperative mechanisms in hemoglobin. Cold Spring Harb. Symp. Quant. Biol. 52, 555-565 http://dx.doi.org/10.1101/SQB.1987.052.01.063

Petschow D., Würdinger I., Baumann R., Duhm J., Braunitzer G., Bauer C. (1977): Causes of high blood O2 affinity of animals living at high altitude. J. Appl. Physiol. 42, 139-143

Pettigrew D. W., Romeo P. H., Tsapis A., Thillet J., Smith M. L., Turner B. W., Ackers G. K. (1982): Probing the energetic of proteins through structural perturbation: sites of regulatory energy in human hemoglobin. Proc. Natl. Acad. Sci. U.S.A. 79, 1849-1853 http://dx.doi.org/10.1073/pnas.79.6.1849

Potterton E., Briggs P., Turkenburg M., Dodson E. (2003): A graphical user interface to the CCP4 program suite. Acta Crystallogr. D Biol. Crystallogr. 59, 1131-1137 http://dx.doi.org/10.1107/S0907444903008126 
Rollema H. S., Bauer C. (1979): The interaction of inositol pentaphosphate with the hemoglobins of highland and low-land geese. J. Biol. Chem. 254, 12038-12043

Safo M. K., Abraham D. J. (2005): The enigma of the liganded hemoglobin end state: a novel quaternary structure of human carbonmonoxy hemoglobin. Biochemistry 44, 8347-8359 http://dx.doi.org/10.1021/bi050412q

Schumacher M. A., Zheleznova E. E., Poundstone K. S., Kluger R., Jones R. T., Brennan R. G. (1997): Allosteric intermediates indicate R2 is the liganded hemoglobin end state. Proc. Natl. Acad. Sci. U.S.A. 94, 7841-7844 http://dx.doi.org/10.1073/pnas.94.15.7841

Shaanan B. (1983): Structure of human oxyhaemoglobin at $2.1 \mathrm{~A}$ resolution. J. Mol. Biol. 25, 31-59 http://dx.doi.org/10.1016/S0022-2836(83)80313-1

Silva M. M., Rogers P. H., Arnone A. (1992): A third quaternary structure of human hemoglobin A at 1.7-A resolution. J. Biol. Chem. 267, 17248-17256

Smith F. R., Lattman E. E., Carter C. W. , Jr. (1991): The mutation beta 99 Asp-Tyr stabilizes Y--a new, composite quaternary state of human hemoglobin. Proteins 10, 81-91 http://dx.doi.org/10.1002/prot.340100202

Smith F. R., Simmons K. C. (1994): Cyanomet human hemoglobin crystallized under physiological conditions exhibits the Y quaternary structure. Proteins 18, 295-300 http://dx.doi.org/10.1002/prot.340180310

Sundaresan S. S., Ramesh P., Sivakumar K., Ponnuswamy M. N. (2009): Purification, crystallization and preliminary $\mathrm{X}$-ray analysis of haemoglobin from ostrich (Struthio camelus). Acta Crystallogr. F Struct. Biol. Cryst. Commun. 65, 681-683 http://dx.doi.org/10.1107/S1744309109019009

Thom C. S., Dickson C. F., Gell D. A., Weiss M. J. (2013): Hemoglobin variants: biochemical properties and clinical correlates. Cold Spring Harb. Perspect. Med. 3

Torrance J. D., Bartlett G. R. (1970): Altitude hypoxia and erythrocyte phosphates. Biochim. Biophys. Acta. 215, 409-411 http://dx.doi.org/10.1016/0304-4165(70)90041-3
Vallone B., Bellelli A., Miele A. E., Brunori M., Fermi G. (1996): Probing the alpha 1 beta 2 interface of human hemoglobin by mutagenesis: Role of the FG-C contact regions. J. Biol. Chem. 271, 12472-12480 http://dx.doi.org/10.1074/jbc.271.21.12472

Voet D., Voet J. G., Pratt C. W. (2008): Fundamentals of Biochemistry: Life at the Molecular Level, John Wiley and Sons

Weber R. E. (2007): High-altitude adaptations in vertebrate hemoglobins. Respir. Physiol. Neurobiol. 158, 132-142 http://dx.doi.org/10.1016/j.resp.2007.05.001

Weber R. E., Jessen T. H., Malte H., Tame J. (1993): Mutant hemoglobins (alpha 119-Ala and beta 55-Ser): functions related to high-altitude respiration in geese. J. Appl. Physiol. 75, 2646-2655

Wells R. M. (1999): Evolution of haemoglobin function: molecular adaptations to environment. Clin. Exp. Pharmacol. Physiol. 26, 591-595 http://dx.doi.org/10.1046/j.1440-1681.1999.03091.x

Winn M. D., Isupov M. N., Murshudov G. N. (2001): Use of TLS parameters to model anisotropic displacements in macromolecular refinement. Acta Crystallogr. D Biol. Crystallogr. 57, 122-133 http://dx.doi.org/10.1107/S0907444900014736

Winn M. D., Ballard C. C., Cowtan K. D., Dodson E. J., Emsley P., Evans P. R., Keegan R. M., Krissinel E. B., Leslie A. G., McCoy A., et al. (2011): Overview of the CCP4 suite and current developments. Acta Crystallogr. D Biol. Crystallogr. 67, 235-242 http://dx.doi.org/10.1107/S0907444910045749

Zhang J., Hua Z., Tame J. R., Lu G., Zhang R., Gu X. (1996): The crystal structure of a high oxygen affinity species of haemoglobin (bar-headed goose haemoglobin in the oxy form). J. Mol. Biol. 255, 484-493 http://dx.doi.org/10.1006/jmbi.1996.0040

Received: January 23, 2014

Final version accepted: June 11, 2014

First published online: August 22, 2014 